\title{
The Pandemic COVID-19 Infection Spreading Spatial Aspects: A Network-Based Software Approach
}

\author{
Basim M. Mahmood \\ bmahmood@uomosul.edu.iq
}

Department of Computer Science
Marwah M. A. Dabdawb

marwa_marwan21@uomosul.edu.iq

Department of Software

College of Computer Science and Mathematics

University of Mosul, Mosul, Iraq

Received on: 20/03/2020

Accepted on: 02/04/2020

\section{ABSTRACT}

Coronavirus or what has been termed COVID-19 is one of the infectious diseases that have been recently classified as a pandemic. Currently, it is considered as the activist and the most dangerous disease that is rapidly spreaded around the world causing thousands of death cases. COVID-19 spreads between people through the contact with the infected ones when they sneeze, cough, or droplets of saliva. In this article, we investigated the impact of the spatial aspects and the movement patterns on COVID-19 infection spreading. We considered three aspects, namely, mobility patterns, curfew (stay-at-home) impact, and the distribution of people within places. The results show that spatial aspects can be considered as one of the factors that play a significant role in spreading the virus.

Keywords: COVID-19, infection Spreading, Pandemic, human mobility, random movement.

$$
\begin{aligned}
& \text { الجوانب المكانية لانتشار عدوى فايروس كورونا: طريقة البرمجيات شبكية التصميم } \\
& \text { مروة مروان عبد العزيز دبدوب } \\
& \text { باسم محمد محمود } \\
& \text { قسم البردجيات } \\
& \text { قسم علوم الحاسوب } \\
& \text { كلية علوم الحاسوب والرياضيات } \\
& \text { جامعة الموصل، الموصل، العراق }
\end{aligned}
$$

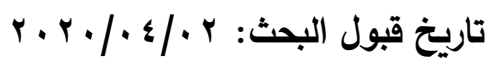

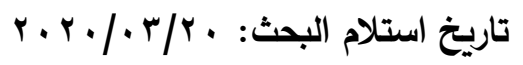

$$
\begin{aligned}
& \text { الملخص } \\
& \text { يعتبر فايروس كورونا المستجد او ما يسمى COVID-19 من الامراض المعدية والذي صنف مؤخرا على انه }
\end{aligned}
$$

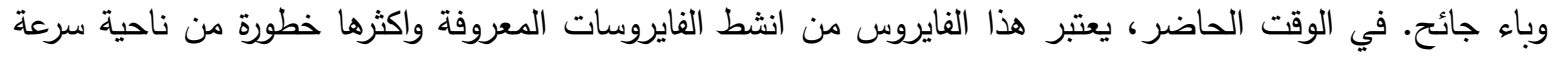

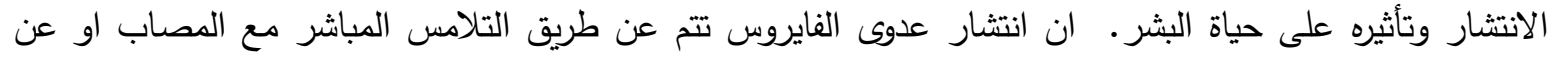

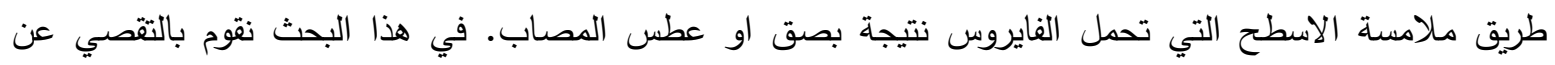

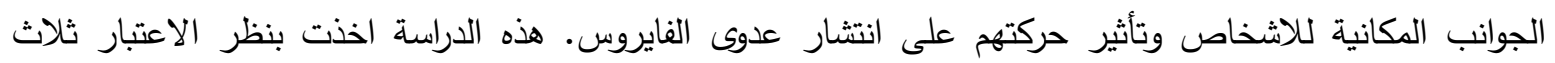

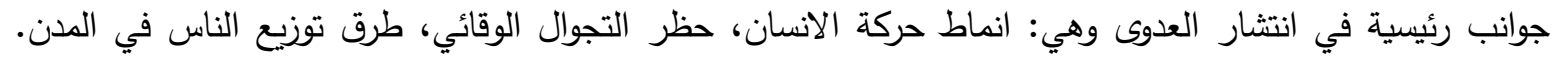

$$
\begin{aligned}
& \text { أظهرت النتائج ان الجوانب الدكانية في انماط حياة الانسان تلعب دورا كبيرا في مدى انتثار عدوى النيان الفايروس. }
\end{aligned}
$$




$$
\text { الكلمات المفتاحية: فايروس كورونا المستجد, انتقال العدوى، الوباء الجائح، حركة الانسان، الحركة العشوائية }
$$

\section{Introduction}

COVID-19 is one of the recently appeared viruses and it is widely spread around the world. It has caused thousands of deaths in many countries around the world [1, 2]. COVID-19 spreads between people through the contact with the infected individuals when they sneeze, cough, or droplets of saliva [3]. This virus is the seventh known coronavirus to infect humans. Two other notable examples include severe acute respiratory syndrome (SARS) and Middle East respiratory syndrome (MERS). Though the virus likely has a zoonotic origin related to the city's Huanan Seafood Market, it is still widely spread between humans around the world causing fever, cough, dyspnea, headache, muscle soreness, and fatigue. About $20 \%$ of the cases are severe, and mortality is approximately $3 \%$ which caused the World Health Organization (WHO) declared a global health emergency on January 30, 2020 [4]. In this kind of virus, the infection primarily depends on the movements of the infected people. This means, the infection is increased whenever the number of visited locations is increased by the infected ones. Therefore, it is needed to understand the mobility (movement) patterns of people and the possibility of these patterns to impact the spreading of the virus. In this context, Song et al. $2010[5,6]$, in their distinguished two articles, characterized the movements' patterns of human based two mechanisms as follows:

i. Exploration: means the tendency of human to explore new locations decreases as the time pass with a probability $P_{n e w}$ that can be formalize as follows [6]:

$$
P_{\text {new }}=\rho S^{-\gamma}
$$

Where $\rho$ and $\gamma$ are the parameters that control the tendency of people to explore and visit new locations in the next step. While $S$ denotes the number of visited locations.

ii. Preferential Return: human behavior in movements reflects an important feature, which is the tendency to return to the most visited locations in the past with a complementary probability of $P_{\text {new }}$ as follows [6]:

$$
P_{\text {ret }}=1-P_{\text {new }}
$$

As the individual moves, the number of visited locations $S$ will be increased to $S+1$ in the next step.

In fact, Song's model is one of the most accurate known models that reflect human movements.

In this work, our objective is to investigate the impact of these two mechanisms on the spreading of the COVID-19 and how these mechanisms can be utilized to decrease the spreading of the virus. To this end, we aim to design software for simulating this kind of work and then perform simulations for the sake of this work's objective. This paper is organized as follows: Section 2 presents several related works. In Section 3, the proposed approach is introduced. Then, the experimental results are presented and discussed in Section 4. Finally, some conclusions and future works are given in Section 5.

\section{Related Works}

Recently, many of the researchers around the world have investigated the issue of COVID-19 infection spread. This is due to the fact that COVID-19 is announced as a 
pandemic by the World Health Organization (WHO). Researchers in [7] investigated the issue of infection spreading of coronavirus and showed that human-to-human contact is the fastest way for transmitting the virus from a person to another. Their work was based on real-data that was collected from the Chinese laboratories and hospitals. However, other researchers try to design models and perform computer simulations aiming at finding some solutions for the issues of coronavirus infection spread. In this context, [8] used a mathematical model to assess whether the isolation and contact tracing are able to control onwards transmission from imported cases of COVID-19. They concluded that case isolation was more effective when there was little transmission before symptom onset and when the delay from symptom onset to isolation was short. Also they found that preventing transmission by tracing and isolating a larger proportion of contacts led to decreasing the effective reproduction number and improved the number of scenarios in which control was likely to be achieved. [9] Estimated the reproductive number $(R O)$ of the novel virus in the early stage of outbreak on the Diamond Princess cruise ship and made a prediction of daily new cases. They showed that the future daily incidence and probable outbreak size is largely dependent on the change of $R 0$. Another study performed by [10] investigated the undocumented infections of COVID-19 prior to implementation of control measures on January 23, 2020 and these undocumented infections substantially contributed to virus transmission. They simulated and explained the rapid geographic spread of COVID-19 and indicated the heightened awareness of the outbreak, increased use of personal protective measures, and travel restriction have been associated with reductions of the overall force of infection. Moreover, [11] presented a work tent to help people understand how infectious disease spreads and the purpose/ consequences of various efforts based on simulation models built on known transmission parameters from published research papers. Other estimation methods were performed on coronavirus infection spread. [12] Estimated the potential scale of the COVID-19 pandemic in the USA from cases 'imported' directly from Wuhan/ China (the first core area of coronavirus). In their work, they used simulations based on transmitting dynamic parameters-- estimated from previous studies and air traffic data also from Wuhan--to the USA model that was used to simulate the growth of the number of infected individuals in Wuhan and in the USA. Another simulation performed by [13], their model performs a validation of the forecasts for the international spread of the coronavirus using the Be-CoDiS mathematical model. The authors concluded that the gap between the predicted and the observed data is increasing and is not negligible and it is needed to recalibrate the model in order to update the forecasts. A model based on global metapopulation disease transmission was proposed by [14] aimed to project the impact of travel limitations on the national and international spread of the coronavirus infection. The model is calibrated based on internationally reported cases.

Based on our extensive search, the literature has a lack in the works that deal with the spatial aspects and the impact of these aspects on infection spread. Therefore, we plan to perform a study that explores and investigates the role of spatial aspects on virus infection spread. Moreover, we are inspired by concepts from complex networks in performing the analysis as well as concepts from software engineering in designing the simulator and the experiments. 


\section{The Proposed Approach}

Before we start describing our approach, we start with the data used in this work. In fact, the data used is divided into two types; first, we used some data collected from worldometer [15], which is a free-access website managed by worldwide teams, research groups, and volunteers. This website provides real-time statistics and facts for most of the world's events (e.g., economic, health, political, etc.). The second type of data used in this work is generated by a simulator we designed for simulating such works. The language used for designing our simulator is NetLogo, which is a multi-agent-based programming language. The environment considered in this simulator represents a virtual squared city divided into blocks. Also, the simulator has the ability to deploy a predefined number of people within the environment. The method of deploying the people is based on the standard distribution observed in real cities (e.g., Uniform, Gaussian, and Power-law). The people in the environment can be static (staying-at-home) or dynamic (moving). For the moving people, we incorporated the human mobility model that is specially used for emulating the behavior of humans in movement in terms of speed and direction. In this context, we use the model that was proposed by [6], which is the most known accurate model. It is also possible to spread a disease (virus) within the environment for the measurement purposes. Also, the infection is transmitted from a node (individual) to another one when the distance between both is 1 meter or less. In this regard, Figure 1 depicts a snapshot of our simulator and the environment used for the simulations. The figure also shows the measurements that can be obtained using the simulator such as, the number of infected people, the number of visited locations by the infected ( or noninfected) people, and the percentage of the infected people to the total population size.

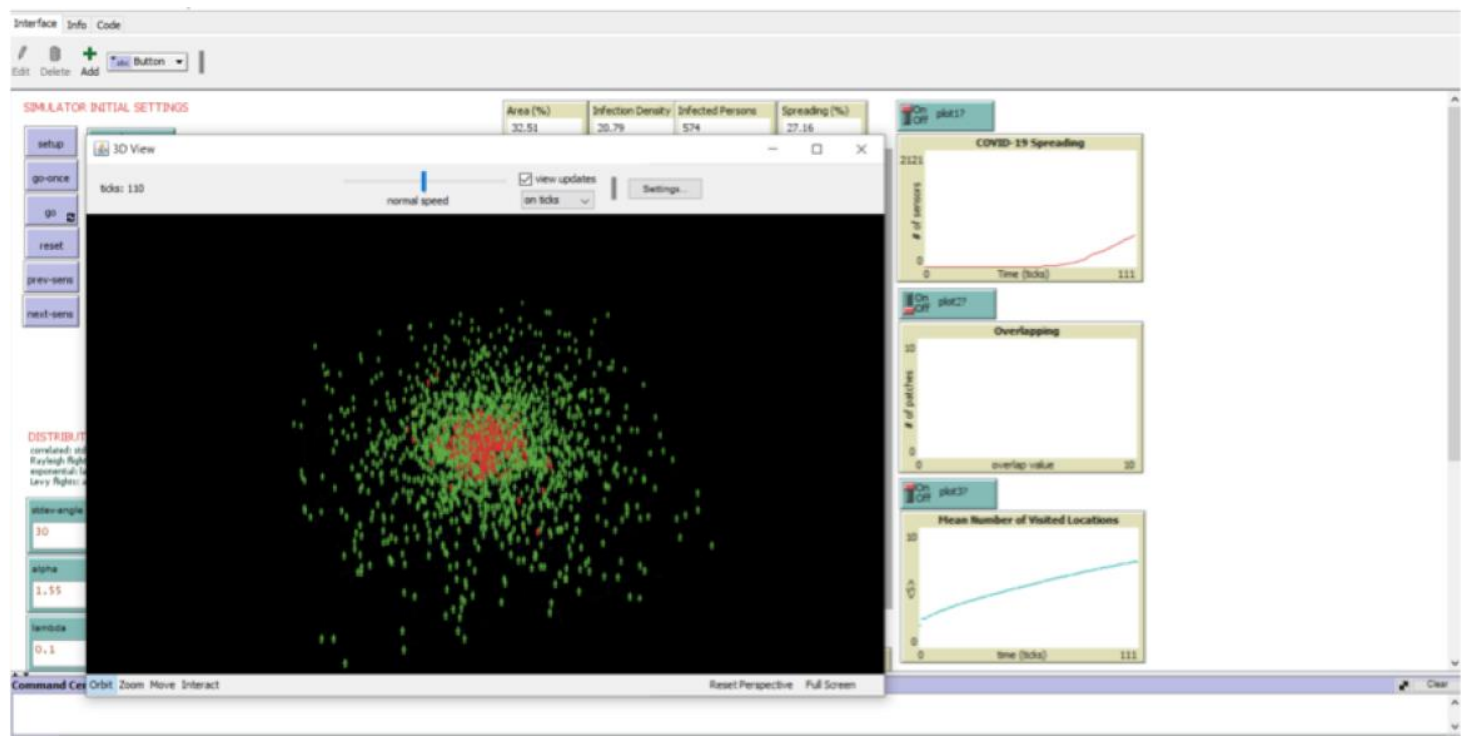

Figure 1: COVID-19 Simulation Environment

Our analysis approach in this work is based on the characteristics of human movements and the spatial aspects (e.g., people distribution). The goal of our simulations is to investigate the impact of the below aspects on COVID-19 infection spreading:

- People's mobility (movement) patterns. 
- Curfew (stay-at-home) state.

- Population distribution.

For the sake of investigating the impact of people's movements on infection spread, we define two groups of simulations as follows:

A. The first group of simulations is called Patterns 1, which is based on using the human mobility model proposed by [6] in both of its mechanisms. In this context, we assume the probability of infection is equal to the probability of visiting new locations as follows:

$$
P_{\text {COVID-19 infection }}=\rho S^{-\gamma}
$$

In our simulations, when an individual does not visit any location $(S=0)$, there is no infection:

\section{$P_{\text {COVID-19 infection }}=0$}

However, visiting more locations increases the probability of getting infected [16, 2].

B. The second group of simulations is called Pattern 2, which is based on using human mobility model with some changes on the first mechanism (Exploration). To do this, we propose to add some randomness to the $P_{\text {new }}$ and reduce the number of visited locations by a random dynamic-variable $N$, this leads the probability of visiting new locations $\left(P N_{\text {new }}\right)$ becomes:

$$
P N_{\text {new }}=\rho(S-N)^{-\gamma}
$$

And the probability of infection is formalized as follows:

$$
P_{\text {COVID-19 infection }}=\rho(S-N)^{-\gamma}
$$

Where $N$ is a random integer dynamic-variable and its value is changed over time, which in turn adds a randomness pattern to the whole movement pattern. During the simulations the value of $N$ is randomly selected at time $t$ to be as follows:

$$
\mathrm{S}(\mathrm{t})>N(t)>0
$$

Furthermore, for investigating the other second aspects in this work (curfew state), we define dynamic and static nodes to simulate both; the moving people and the people who stay at their homes respectively. For the third aspect (people distribution), we programmed our simulator to deploy the nodes in three forms, Gaussian, Power-Law (long-tail), and Uniform distributions.

Now, after defining our goals and preparing our simulator, we are able to perform our simulations. It should be mentioned that each simulation performed in this work represents the average of 50 runs. This is because our model is almost dynamic and each simulation may produce slightly different results. Practically, this strategy guarantees our results to be reliable. Moreover, in the simulations, we deployed 5000 nodes (persons) within the simulation environment. For the first aforementioned aspect, the people are distributed based on power-law distribution, which is the way that people are distributed in metropolitan cities [17]. Finally, in the simulation environment, we deployed the COVID19 (one infected person) in the center of the environment aiming at considering the worst case, which is desired in our simulations.

\section{Experimental Results}

\subsection{Mobility Behavior Impact}

After performing the simulations, the results were very interesting. We found that when people change their regular patterns in movement, the probability of getting infected 
by COVID-19 is decreased. The change in pattern, in our case, means decreasing the number of visited locations. More precisely, when following a random pattern in movement, the number of visited locations is decreased and that eventually decreases the infection spread rate. The result of Pattern 1 reflected relatively close numbers and results compared to the dataset presented in worldometer [15] when considering the average number of infected people. Figure 2, depicts the simulations of Pattern 1 and the proposed Pattern 2. According to this figure, Pattern 2 outperforms the results obtained by Pattern 1.

Furthermore, we performed additional analysis to this result by plotting the quartiles of the two approaches (boxplot). Figure 3 shows that Pattern 2 reflects a stable and lower infection rate compared to Pattern 1. This actually makes our results more reliable and statistically significant.

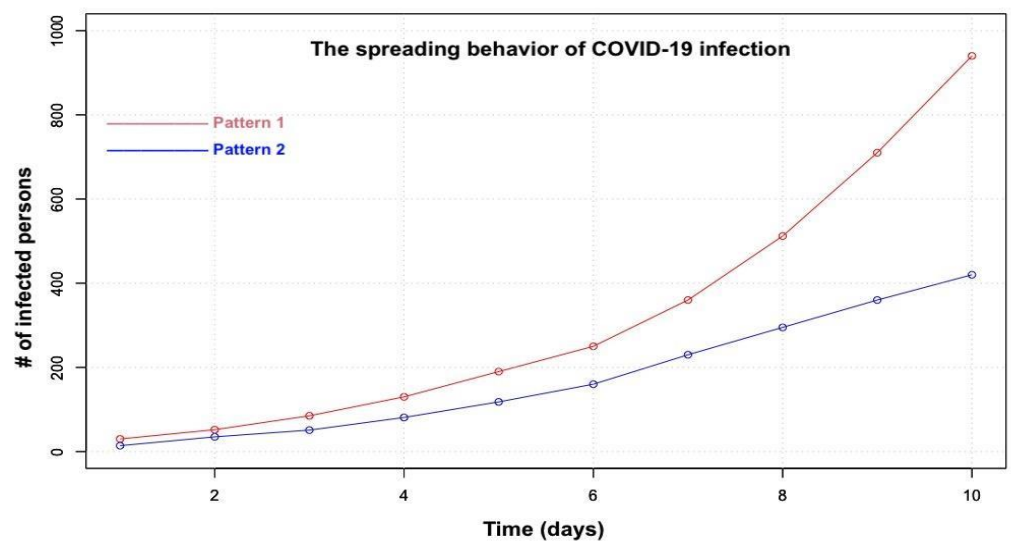

Figure2: The results of the simulations for Pattern 1 and Pattern 2.

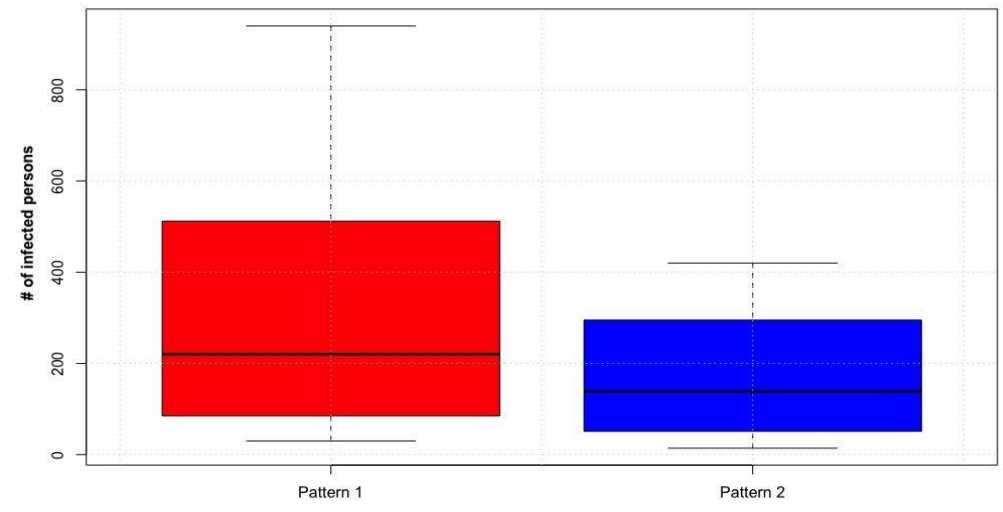

Figure 3: The quartiles of the results of Pattern 1 and Pattern 2.

\subsection{Curfew Impact}

Curfew is a law stating that people must stay inside their houses at particular times (night/day/both) during wars, epidemic/pandemic, or emergency cases [18]. Typically it refers to the situation when individuals are required to return and stay in their homes. Such an order may be issued by public authorities or the officials of a city/province/state/ country [19]. 
As mentioned, reducing the number of visited locations can reduce the infection spreading rate. The case of curfew forces people not to move and causes the new visited locations approaches 0 . This leads to the probability of getting infected is equal to 0 (as mentioned in Section 3).

In this work, we simulated the curfew situation by involving static and mobile (dynamic) nodes. The static nodes are the individuals who are subject to the curfew (stay at their homes), while the mobile nodes are the individuals who are authorized to move (e.g., emergency teams or policemen). These nodes are distributed within the simulation environment. Figure 4 depicts how individuals (static and mobile) are deployed within the environment.

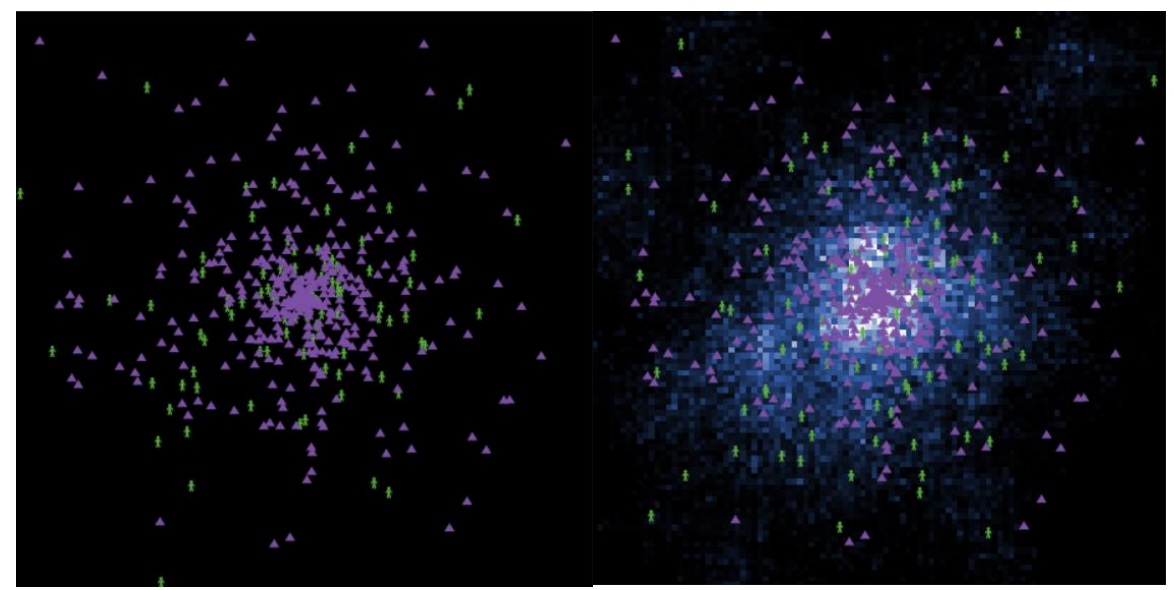

Figure 4: On the left, the figure shows how the people (static in purple color and mobile in green color) deployed within the environment. The right figure shows the environment with the areas in dark blue color (less visited,) white color (most visited), and black color (not visited). The white locations are caused by the moving people.

Based on the fact that in modern cities, about 20-30\% (in average) of the locations is barely accessible due to natural barriers (e.g., swamps, hills, lakes, deserts, ... etc.) [20]. This means that less than $80 \%$ of a city is accessible by people. In fact, we took this fact into considerations in our simulations where the maximum percentage of visited locations does not reach $80 \%$ of the city locations. Therefore, if a city is highly populated, the maximum percentage of visited locations does not reach $100 \%$ of the total city size and $100 \%$ of the population live in approximately $80 \%$. According to the experimental results, reducing the number of visited locations by $10 \%$, the percentage of visited locations is reduced to $4 \%$ of the total locations within the environment. In the case of curfew, the people who are allowed to move represents fewer than $10 \%$ of the total population size according to [21]. This means if the curfew is applied to $90 \%$ of the population, the probability of getting infected using Equation 1 is approximately 0.14 , which is interesting and significantly less in regular cases (no curfew). This means curfew plays a very important role in decreasing the infection rate within a city as shown in Figure 5. 


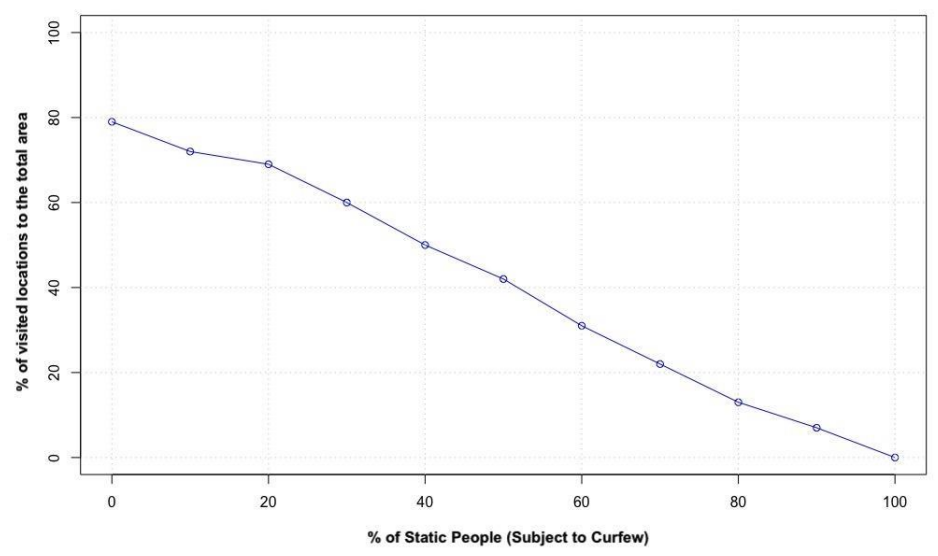

Figure 5: Percentages of visited areas when varying the static people.

\subsection{People Distribution Impact}

In most of the metropolitan cities [17], people distribution follows a power-law, where people are dense in the center of the city and this density is significantly decreased reaching to the edges of the city. On other hand, the population distribution in other cities may follow Uniform distribution, where people are uniformly deployed in city areas, or Gaussian distribution, where the people are a little more in the center than in other city areas. In this work, we designed our simulator to be able to simulate such distributions in the environment. Figure 6 portraits our simulator when using different kinds of distributions for the population. According to [22], population distribution is considered a crucial factor that contributes in increasing or decreasing the infection spreading rate. For instance, in the cities (or counties) where the people are uniformly deployed, the infection can be at a lower rate. In contrast, the highly populated cities where people are exponentially deployed (e.g., power-law) from the center of the city, the infection spreading is significantly increased affecting more people due to the existence of crowd areas.
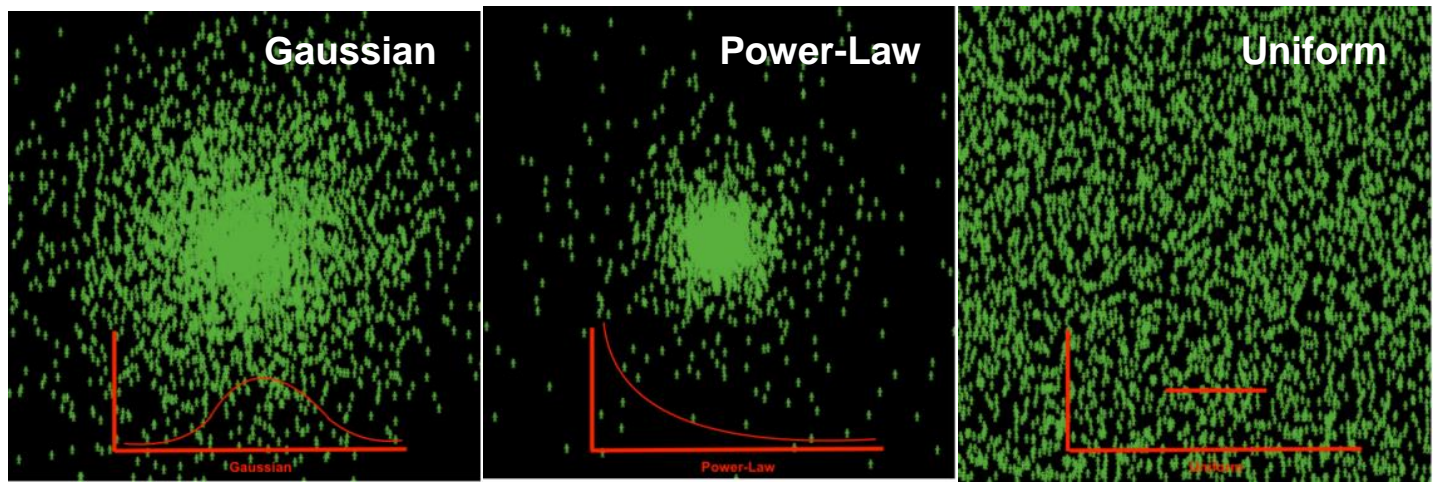

Figure 6: Different population distributions in cities.

In the experimental results, we used the three distributions for deploying the people within the city, namely; Gaussian, Power-Law, and Uniform. As expected, the number of infected people by the virus is high when using power-law and there is a low rate of 
infection when using uniform distributions. It should be mentioned that the settings of the simulator were as follows: population size was 5000, people move based on human mobility model, the simulations starts with one infected person, the duration time of each simulation is 12 hours (the corresponding time in our simulation) considering the worst case during the daytime when the people move actively. Table 1 presents the percentages of each distribution and Figure 7 shows snapshots of the simulations for the three cases.

Table 1: The percentage of infected people by the virus when varying the distribution.

\begin{tabular}{|c|c|c|c|}
\hline & $\begin{array}{c}\text { Gaussian } \\
\text { Distribution }\end{array}$ & $\begin{array}{c}\text { Power-Law } \\
\text { Distribution }\end{array}$ & $\begin{array}{c}\text { Uniform } \\
\text { Distribution }\end{array}$ \\
\hline $\begin{array}{c}\text { \% Of infected } \\
\text { people }\end{array}$ & $58.60 \%$ & $92.19 \%$ & $27.3 \%$ \\
\hline
\end{tabular}

In fact, our results reflect the case of the USA, in which the metropolitan cities/states such as New York, California, and New Jersey have recorded high rates of infection by the COVID-19 [15]. The other states that are not highly populated and follow almost a uniform distribution in deploying people within the city have recorded the least rates of infection such as Alaska, Montana, and South Dakota [15].
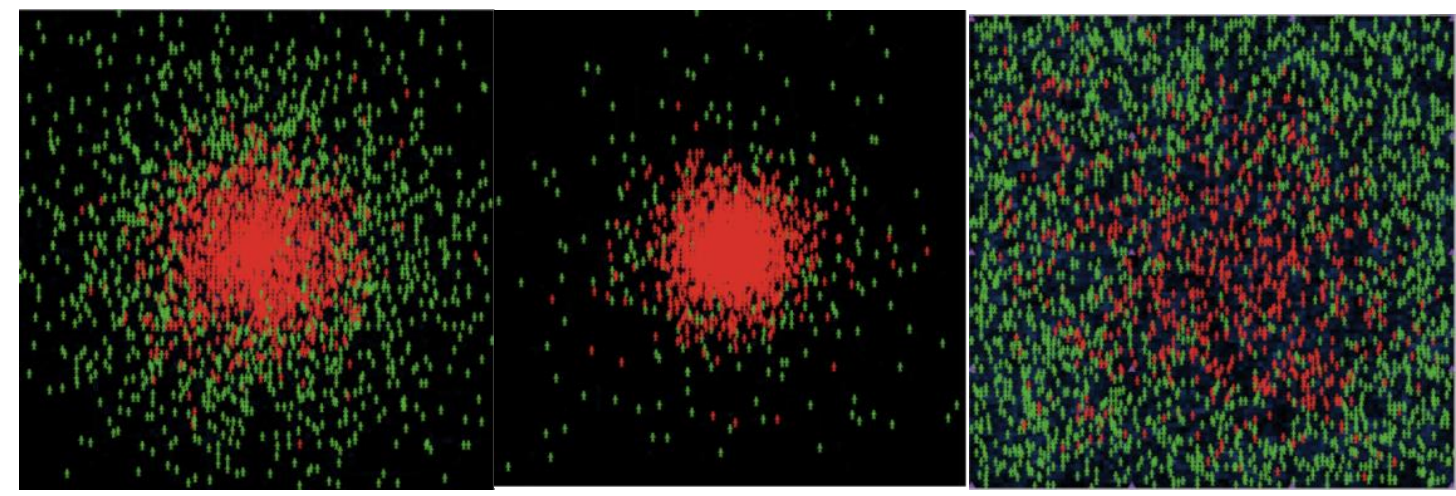

Figure 7: The simulations of the three distributions considered in this work. The red nodes are the people who are infected by the virus, while the green nodes are not infected

\section{Conclusion and Future Works}

In this work, we studied the impact of mobility patterns and the spatial aspects of people on the COVID-19 infection spread. To this end, we considered three main aspects that impact the infection spread, namely, mobility patterns, curfew state (stay-at-home), and population distribution. The experimental results showed that the movement patterns of humans can be considered as one of the factors that impact the COVID-19 infection spread rate. In case of movements, the more visited locations by people, the higher the infection rate obtained. Since humans followed a particular pattern when moving from one place to another [5, 6], the results showed that when adding some randomness to this pattern, the number of visited locations is decreased, which eventually decreases the infection spread rate. The second aspect we investigated is the impact of forcing people to stay at their homes (curfew state) on the COVID-19 infection spread. The results showed that when 
forcing $10 \%$ of the population to be under curfew state, the infection spread rate decreased to $4 \%$, which is interesting. The last investigation in this work is the impact of population distribution on infection spread rate. We found that when the population distribution of a city followed a power-law, the infection spread rate can be higher than the other known distributions. Also, when people are uniformly deployed in a city, the infection spread rate is low. This means the metropolitan cities are more exposed to get a high rate of infection.

Finally, since this work is on-going and currently under further investigations, we are performing more deep analysis on the results obtained using advanced statistical tools. We also plan to perform more simulations and vary the population size as well as involving more infected cases within the simulation environment. We also plan to build a model for predicting the areas that are more exposed to the infection based on the features of human movements and the strategies that COVID-19 follows in spreading. 


\section{REFERENCES}

[1] Lipsitch, Marc, David L. Swerdlow, and Lyn Finelli. "Defining the epidemiology of Covid-19—studies needed." New England Journal of Medicine (2020).

[2] Bai, Yan, Lingsheng Yao, Tao Wei, Fei Tian, Dong-Yan Jin, Lijuan Chen, and Meiyun Wang. "Presumed asymptomatic carrier transmission of COVID-19." Jama (2020).

[3] Xu, Zhe, Lei Shi, Yijin Wang, Jiyuan Zhang, Lei Huang, Chao Zhang, Shuhong Liu et al. "Pathological findings of COVID-19 associated with acute respiratory distress syndrome." The Lancet Respiratory Medicine (2020).

[4] Bernheim, Adam, et al. "Chest CT findings in coronavirus disease-19 (COVID-19): Relationship to duration of infection." Radiology (2020): 200463.

[5] Song, Chaoming, Zehui Qu, Nicholas Blumm, and Albert-László Barabási. "Limits of predictability in human mobility." Science 327, no. 5968 (2010): 1018-1021.

[6] Song, Chaoming, Tal Koren, Pu Wang, and Albert-László Barabási. "Modelling the scaling properties of human mobility." Nature Physics 6, no. 10 (2010): 818-823.

[7] Guan, Wei-jie, Zheng-yi Ni, Yu Hu, Wen-hua Liang, Chun-quan Ou, Jian-xing He, Lei Liu et al. "Clinical characteristics of 2019 novel coronavirus infection in China." MedRxiv (2020).

[8] Hellewell, Joel, et al. "Feasibility of controlling COVID-19 outbreaks by isolation of cases and contacts." The Lancet Global Health (2020).

[9] Zhang, Sheng, et al. "Estimation of the reproductive number of Novel Coronavirus (COVID-19) and the probable outbreak size on the Diamond Princess cruise ship: A data-driven analysis." International Journal of Infectious Diseases 93 (2020) 201204.

[10] Li, Ruiyun, et al. "Substantial undocumented infection facilitates the rapid dissemination of novel coronavirus (COVID-19)." medRxiv (2020).

[11] Guopeng, Z. H. O. U., and C. H. I. Chunhua. "A model simulation study on effects of intervention measures in Wuhan COVID-19 epidemic." medRxiv (2020).

[12] Li, Dalin, et al. "Estimating the scale of COVID-19 Epidemic in the United States: Simulations Based on Air Traffic directly from Wuhan, China." medRxiv (2020).

[13] Ivorra, Benjamin, and Angel M. Ramos. "Validation of the forecasts for the international spread of the coronavirus disease 2019 (COVID-19) done with the BeCoDiS mathematical model." ResearchGate Preprint 28 (2020): 1-7.

[14] Chinazzi, Matteo, et al. "The effect of travel restrictions on the spread of the 2019 novel coronavirus (COVID-19) outbreak." Science (2020). 
[15] Collins, Peter. "Worldometers: real time world statistics." Worldometers. info. Dadax 9 (2020).

[16] Chen, Huijun, Juanjuan Guo, Chen Wang, Fan Luo, Xuechen Yu, Wei Zhang, Jiafu $\mathrm{Li}$ et al. "Clinical characteristics and intrauterine vertical transmission potential of COVID-19 infection in nine pregnant women: a retrospective review of medical records." The Lancet (2020).

[17] Prein, Andreas F., Wolfgang Langhans, Giorgia Fosser, Andrew Ferrone, Nikolina Ban, Klaus Goergen, Michael Keller et al. "A review on regional convectionpermitting climate modeling: Demonstrations, prospects, and challenges." Reviews of geophysics 53, no. 2 (2015): 323-361

[18] Valentine, Gill. "Public space and the culture of childhood." Routledge (2017).

[19] Staeheli, Lynn, and Donald Mitchell. "The People's Property?: Power, Politics, and the Public." Routledge, (2016).

[20] Geard, Nicholas, James M. McCaw, Alan Dorin, Kevin B. Korb, and Jodie McVernon. "Synthetic population dynamics: A model of household demography." Journal of Artificial Societies and Social Simulation 16, no. 1 (2013): 8.

[21] Hucklesby, Anthea. "Electronically monitored curfews." Electronically monitored punishment: International and critical perspectives (2013): 228.

[22] Volz, Erik M., Joel C. Miller, Alison Galvani, and Lauren Ancel Meyers. "Effects of heterogeneous and clustered contact patterns on infectious disease dynamics." PLoS computational biology 7, no. 6 (2011). 